BOLESŁAW RACIĘSKI

Wydział „Artes Liberales”

Uniwersytet Warszawski
Images

vol. XXVIII/no. 37

Poznań 2020

ISSN 1731-450X

\title{
Przyszłość już była. Dystopie w najnowszym kinie science fiction Ameryki Łacińskiej
}

\begin{abstract}
Racięski Bolesław, Przyszłość już była. Dystopie w najnowszym kinie science fiction Ameryki Łacińskiej [The future has already happened. Dystopias in contemporary Latin American science fiction cinema]. "Images" vol. XXVIII, nr 37. Poznań 2020. Adam Mickiewicz University Press. Pp. 167-175. ISSN 1731-450X. DOI 10.14746/i.2020.37.10.

This paper examines the various ways in which contemporary Latin American science fiction films contest the neocolonial and neoliberal narratives, dominant in the region since the 20th century. I identify and examine strategies that filmmakers employ to challenge the common understanding of such notions as time, modernity and technological progress. I outline the visions of dystopias presented in the examined films, while also analyzing the counter-narratives introduced by filmmakers, which are mostly focused on creating a new, hybrid identity for a future citizen.
\end{abstract}

KEYwords: dystopia, Latin American Cinema, neocolonialism, neoliberalism, science fiction

„Czy my nie mamy prawa do Marsjan?” - pyta Julio, bohater argentyńskiego filmu dokumentalnego Estrellas (Gwiazdy, 2007, reż. Federico León, Marcos Martínez). „My” to w tym przypadku mieszkańcy Villa 21, biednej dzielnicy Buenos Aires, żyjący z piętnem „trzeciego świata". Julio rozumie filmowy biznes, bo zawodowo zajmuje się scoutingiem dla reżyserów, którzy chcą pokazać w swoich filmach to, co kpiąco nazywa się pornomisería [1]: latynoską biedę i nędzę. Dekadę wcześniej zawitał do Julia sam Alan Parker, szukający lokacji do Evity (1996), ale srogo się zawiódł - w rozpadających się domach stały telewizory, przez co okolica sprawiała wrażenie „zbyt cywilizowanej”. Julio wierzy jednak, że nawet w Villa 21, w warunkach dalece odbiegających od hollywoodzkich studiów, można nakręcić film science fiction, chociażby z poprzebieranymi sąsiadami $\mathrm{w}$ rolach głównych.

Większość latynoamerykańskich twórców kinowego science fiction jest trochę jak Julio: działają na uboczu, bez zakorzenienia w wielkich tradycjach, opowiadając nie o centrach tego świata, ale kreśląc lokalne fantazje. I podobnie jak Julio, ich twórczość często wyrasta $z$ buntu i potrzeby zanegowania popularnego status quo oraz wejścia $\mathrm{w}$ dyskusję z dominującymi siłami. W tym artykule pragnę pokazać, $\mathrm{w}$ jaki sposób wybrane filmy science fiction negują dwie splecione ze 
sobą narrację - neoliberalną i kolonialną - przez lata rozrywające Amerykę Łacińską, w tym przede wszystkim kojarzone z nimi pojmowanie postępu oraz temporalności.

Każde rozważania poświęcone Ameryce Łacińskiej w ujęciu totalnym zacząć należy od wyjaśnienia wątpliwości, która winna nasuwać się automatycznie: czy można cały region sprowadzać do jednej masy, ignorując partykularyzmy każdego z przynależących do niego krajów i kultur? Jest to niezwykle ryzykowne i zawsze wymaga uzasadnienia: ja kieruję się przekonaniem, że omawiane filmy wyraźnie odwołują się do pewnej wspólnoty kontynentalnych doświadczeń, na przykład rządów wojskowych dyktatur i - co dla tego tekstu szczególnie istotne skutków kolonializmu oraz polityk neoliberalnych lat osiemdziesiątych i dziewięćdziesiątych XX wieku[2].

Niezwykły wynalazek

Andrea Bell zauważa, że kraje Ameryki Łacińskiej długo nie mogły doczekać się „,swojego Gernsbacka albo Campbella”[3], to znaczy autorytetu, który promowałby początkujących twórców science fiction i potrafiłby stworzyć wyrazisty ruch (takie pojawiły się dopiero w latach osiemdziesiątych, wraz z gwałtownym rozwojem quasi-amatorskich zinów). Jednak technologiczny rozwój i postęp nauki były dla popularnych w regionie narracji niezwykle istotne już od XIX wieku: Roberto González Echevarría pisze, że naukowy dyskurs był najważniejszym narzędziem legitymizacji nowych idei w Ameryce Łacińskiej[4]. Warto dodać, że dla generalnej historiografii latynoamerykańskiej fantastyki naukowej pewnym problemem okazało się zjawisko realizmu magicznego - to tym terminem często określano literaturę, która w innych okolicznościach niewątpliwie doczekałaby się miana science fiction: Wynalazek Morela (Adolfo Bioy Casares, 1940) albo Tlön, Uqbar, Orbis Tertius Borgesa (1940)[5]. Jak zauważyła Ursula Le Guin: „większość krytyków literackich używa określenia realizm magiczny dla fantazji, które aprobują, a tych popularnych po prostu nie zauważają"[6].

W kinie latynoamerykańskim konwencje science fiction pojawiają się już w latach trzydziestych, a zaczynają być wyraźnie zauważalne od połowy zeszłego stulecia, przede wszystkim w meksykańskim kinie rozrywkowym, na przykład Statku potworów (La nave de los monstruos, 1960, reż. Rogelio A. González) albo Santo kontra inwazja Marsjan (1967, reż. Alfredo B. Crevenna). W kontekście niniejszego

[2] To zagadnienie poruszam również w: B. Racięski, Argentyna, Meksyk, Brazylia oraz pozostałe kinematografie latynoamerykańskie, [w:] Historia kina, t. 4: Kino końca wieku, red. T. Lubelski, I. Sowińska, R. Syska, Kraków 2019, s. 605-640.

[3] A. Bell, Science Fiction in Latin America: Reawakenings, „Science Fiction Studies” 1999, nr 3, vol. 26, s. 441.

[4] Zob. R. González Echevarría, Myth and Archive: A Theory of Latin American Narrative, Cambridge,
New York, Port Chester, Melbourne, Sydney 2006, s. 103.

[5] Borges napisał zresztą wstęp do argentyńskiego wydania Kronik marsjańskich Raya Bradbury'ego (1950).

[6] U. Le Guin, Introduction, [w:] The Norton Book of Science Fiction: North American Science Fiction, 1960-1990, red. U. Le Guin, B. Attebery, New York 1993 , s. 29. 
artykułu[7] istotniejsze wydają mi się jednak elementy science fiction wykorzystywane przez twórców zaangażowanych politycznie. Takie filmy jak przynależące do brazylijskiego zjawiska Cinema Novo Brazylia, rok 2000 (1969, reż Walter Lima Jr.) i Schron przeciwatomowy (Abrigo Nuclear, 1981, reż. Roberto Pires) wyraźnie krytykowały ograniczenia demokracji i wojskowe reżimy[8]. Owa strategia kojarzyć się musi oczywiście z najważniejszą cechą science fiction: jak pisał Fredric Jameson, ten nurt opowiada nie o naszych oczekiwaniach, ale o teraźniejszości, stwarzając impuls ku temu, byśmy zdystansowali się od tego, co wokół i zdobyli na głębszą kontemplację rzeczywistości[9]. Tą właśnie drogą idą najciekawsze współczesne filmy tego gatunku z Ameryki Łacińskiej.

Wizje przyszłości w latynoskim science fiction XXI wieku oparte są na maksymalizacji problemów, które dotknęły region w latach osiemdziesiątych i dziewięćdziesiątych poprzedniego stulecia: agresywne polityki neoliberalne doprowadziły do radykalnych dysproporcji w poziomie życia, do społecznych wykluczeń, uzależnienia rządów od globalnych korporacji[10]. Filmy te jednocześnie nawiązują do dziedzictwa kolonializmu, dążącego do eliminacji przejawów lokalnego oporu.

Być może najbardziej wyrazistą koncepcję przedstawiają Kleber Mendonça Filho i Juliano Dornelles w brazylijskim Bacurau (2019). W niedalekiej przyszłości nowoczesne techniki pozwolą odciąć małą wioskę od wszelkich środków komunikacji ze światem, dzięki czemu bogaci Amerykanie mogą urządzać bezkarne (do czasu) polowania na ubogich Brazylijczyków, po kolei znikających z map satelitarnych. Wśród kilku innych pozycji, których autorzy starają się krytycznym okiem spojrzeć na rozwój regionu zdominowanego przez obce wpływy (jeszcze na przykład meksykański 2033, 2009, reż. Franscesco Laresgoiti, brazylijski Branco Sai, Preto Fica [Czarni wchodza, biali wychodza] 2014, reż. Adirley Queirós) warto wyróżnić rozbudowane wizje dystopii[11] w meksykańskim Podłącz się (Sleep Dealer, 2006, reż. Alex Rivera) oraz brazylijskiej Uma História de Amor e Fúria (Historia o miłości i furii, 2013, reż. Luiz Bolognesi)

[7] O funkcjach pełnionych przez filmy z Santo w roli głównej piszę w: B. Racięski, Zapaśnik bawi i uczy. Społeczne funkcje filmów o Santo [w:] Bękarty kinematografii, czyli rzecz of filmach nie(do)cenionych, red. B. Racięski, F. Nowak, J. Łuniewicz, Wrocław 2014, S. $113-126$.

[8] Warto wspomnieć tutaj również argentyńskiego Mężczyznę patrzącego na południowy wschód (Hombre mirando al sudeste, 1986, reż. Eliseo Subiela): krytyka praktyk wojskowej junty zamaskowana została przez historię człowieka, który twierdzi, że przybył $\mathrm{z}$ kosmosu i mierzyć się musi z opresyjną instytucją zakładu dla psychicznie chorych.

\section{Maksymalizacje neoliberalizmu}

[9] Zob. F. Jameson, Progress versus Utopia; or, can we imagine the future?, „Science Fiction Studies” 1982, nr 27, s. 4.

[10] Zob. np. J. Petras, H. Veltmeyer, Neoliberalism and imperialism in Latin America: dynamics and responses, „International Review of Modern Sociology” 2007, vol. 33, s. 27-59.

[11] O nagminnym, choć nieprawidłowym utożsamianiu dystopii z antyutopią zob. np. K.M. Maj, Antyutopia - o gatunku, którego nie było, „Zagadnienia Rodzajów Literackich" 2019, t. 62, nr 4, s. 9-29; F. Jameson, Archaeologies of the Future: The desire called utopia and other science fictions, New York 2005; D. Alihodžić, S. Veseljevic Jerkovic, The Boundaries of Dystopian Literature: The genre in context, Tuzla 2016. 
W pierwszym z tych filmów oglądamy futurystyczne przetworzenie tematu, który według niektórych badaczy wykiełkował już właściwie w osobny gatunek kina meksykańskiego[12]: emigracji do Stanów Zjednoczonych. W filmie Alexa Rivery Meksykanie nie przekraczają jednak granicy, zamiast tego podłączają się do specjalnego systemu, który umożliwia zdalne sterowanie dronami i innymi maszynami na terenie tego kraju. Socjolog David Spencer pisze o Meksyku z początku XXI wieku: „Okoliczności, które napędzają migrację - brak pracy za przyzwoite stawki, $\mathrm{z}$ dodatkami i w przyzwoitych warunkach, a także brak porządnych programów społecznych - nie polepszyły się lub nawet uległy pogorszeniu wraz z pogłębianiem się w Meksyku polityki neoliberalnej"[13]. Świat Podłącz się jest dalszym etapem tego pogarszania, w którym dosłowność zastąpiła już metaforę: Jean-François Lyotard pisał, że pod przykrywką „rozwoju” często kryje się nieludzkość systemu[14] i faktycznie bohaterowie filmu Rivery, $z$ wystającymi z ciała kablami i kamerami zastępującymi oczy, podają w wątpliwość definicje „człowieka”. Są oni również ucieleśnieniem marksistowskiej alienacji: fizycznie odcięci zostali nie tylko od świata wokół, ale również od miejsca wykonywanych usług, od których dzieli ich silnie ufortyfikowana granica państwa. W końcu Podłącz się kreśli ponurą wizję dostępu do dóbr przyrody: nad meksykańską wodą władzę sprawuje prywatna korporacja, surowo każąca za próby naruszenia zasad reglamentacji. Odbijają się tutaj echa meksykańskich reform wodnych i wprowadzenia opłat za wodę, na które nie może pozwolić sobie wielu farmerów[15].

Ograniczenie dostępu do wody jest podstawą organizacji porządku społeczno-gospodarczego w Rio de Janeiro 2096 roku, przedstawionym w ostatnich fragmentach Uma História de Amor e Fúria. Także tutaj, jak w Podłacz się, władzę sprawuje monumentalna korporacja, egzekwująca zakazy i nakazy poprzez zmilitaryzowaną siłę oraz usankcjonowaną przemoc. Szklanka wody jest, jak stwierdza główny bohater, "droższa od whisky”, a on sam huczące wodospady może oglądać co najwyżej na ekranowych projekcjach. Fabularna konstrukcja filmu zaklęty w ptaka mężczyzna $\mathrm{z}$ ludu Tupinambá powraca do ludzkiego ciała w kolejnych etapach historii Brazylii - pozwala prześledzić, jak roślinność zastępowana jest przez monumentalne wieżowce, zasoby naturalne Ameryki Łacińskiej zostają przekształcone w towar, a wielkie, multinarodowe korporacje przejmują władzę nad społeczeństwem. Niezwykle podobną wizję prezentuje również inna animacja, argentyński Cóndor Crux (tutaj Buenos Aires zostaje zamienione w Darwin City, nad którym panuje Gloria Mundi Conrporation) oraz wspomniany wyżej meksykański 2033.

[12] Zob. T.G. Deveny, Migration in Contemporary Hispanic Cinema, Lanham 2012, s. 190.

[13] D. Spencer, Clandestine Crossings: Migrants and coyotes on the Texas-Mexico border, Ithaca 2009, s. 20.
[14] Zob. J.-F. Lyotard, The Inhuman. Reflections on Time, przeł. G. Bennington, R. Bowlby, Stanford 1998, s. 2.

[15] Zob. D.M. Liverman, S. Vilas, Neoliberalism and Latin American Environments, Annual Review of „Environment and Resources" 2006, nr 1, vol. 31, s. 341. 
Wizje latynoamerykańskich dystopii są zatem, co dla tego zjawiska niezwykle charakterystyczne, oparte na „wyobrażeniu świata, w którym krytykowane aspekty teraźniejszości rozrosły się i oszalały”[16]. Co jednak szczególnie istotne, filmy te nie są co najwyżej ostrzegawczym „kanarkiem w klatce”[17], ale przedstawiają również interesujące strategie oporu. Oparte są one na podważaniu popularnego rozumienia tego, co Barbara Adam nazwała „najbardziej skutecznym narzędziem kolonializmu" [18]: czasu.

Gdy Siergiej Eisenstein zwiedzał Meksyk, zauważył, że w kraju poszczególne etapy powszechnie kojarzone z rozwojem cywilizacyjnym istnieją raczej obok siebie, zamiast następować po sobie[19]. I jeżeli radzieckiemu reżyserowi nie udało się w pełni oddać tego zjawiska w filmie Niech żyje Meksyk! (1931/1979), to stosowanie synchronii w miejsce diachronii jest dziś podstawową strategią latynoamerykańskiego kina science fiction, gdy stara się przedstawić krytyczne wizje przyszłości.

Badacze postkolonialni zwracają uwagę, że w procesach kolonizacji te sposoby postrzegania rzeczywistości przez kolonizowanych, które różniły się od wizji kolonizujących, przedstawiane były jako anachronizmy[20], przesądy, wynalazki prymitywne i przednowoczesne. Anne McClintock pisze, że kolonizowane ludy traktowane były jako atawistyczne, irracjonalne, istniejące w „wiecznie przeszłym czasie” [21]. Czas linearny zakłada wyraźne oddzielenie epok następnych od poprzednich, tłumaczy heterogeniczność na homogeniczność za pomocą szeregu wykluczających gestów. W centrum takiego pojmowania czasu stoi oczywiście koncepcja postępu, napędzająca imperializm od XV stulecia i bezlitośnie anihilująca przeszłość[22]. Jessica Langer dodaje, że kolonialna ideologia postępu zawiera w sobie dążenie do rozwoju technologicznego[23], w którym nowe wynalazki całkowicie zastępują poprzednie. Kontestacja takiego podejścia jest charakterystyczna właśnie dla najciekawszych latynoskich wizji science fiction.

W Podłącz się złowroga korporacja Del Río Water napotyka na opór Majańskiej Armii Wyzwolenia Wody, w oczywisty sposób nawiązującej do Zapatystowskiej Armii Wyzwolenia Narodowego (Ejército Zapatista de Liberación Nacional - EZLN). EZLN walczy o prawa rdzennych mieszkańców Meksyku, przypominając o tych, którzy zostali wyłączeni ze społeczeństwa przez galopującą modernizację kraju

[16] J. Langer, The Shapes of dystopia. Boundaries, hybridity and the politics of power, [w:] Science Fiction, Imperialism and the Third World, red. E. Hoagland, R. Sarwal, Jefferson, London 2010, s. 171.

[17] Zob. ibidem.

[18] B. Adam, Time, Cambridge 2004, s. 136.

[19] Zob. P.A. Schroeder Rodriguez, Marxist historiography and narrative form in Sergei Eisenstein's iQue viva Me'xico!, „Rethinking Marxism” 2009, nr 2, vol. 21, S. 229.

\section{Po(d)stęp}

[20] Zob. B. Cua Lim, Translating Time. Cinema, the Fantastic, and Temporal Critique, Durham 2009, s. 16. [21] A. McClintock, Imperial Leather: Race, Gender, and Sexuality in the Colonial Contest, Abingdon-on-Thames 2013, s. 30.

[22] Zob. B. Cua Lim, op.cit., s. 45.

[23] Zob. J. Langer, Postcolonialism and Science Fiction, Houndmills, Basingstoke, Hampshire, New York 2011, s. 130. 
oraz politykę neoliberalną. Jednym z celów zapatystów jest stworzenie alternatywnego do kapitalistycznego porządku[24]. W filmie Rivery partyzanci nawiązują do swoich prekolumbijskich korzeni już w nazwie: tym samym w futurystyczną wizję przyszłości wprowadzony zostaje element anachroniczny, który (momentami zupełnie dosłownie) rozsadza kapitalistyczny porządek. Mimo postępu („postępu”?) manifestującego się w rozwoju technologii i techniki anachronizmy nie pozwalają o sobie zapomnieć, ciągle stawiając opór.

W Uma História de Amor e Fúria zaburzenie linearności czasu widać jeszcze wyraźniej: protagonista Abeguar, dzięki wymykającej się racjonalnemu pojmowaniu mocy, powraca do ludzkiej formy w kolejnych fazach rozwoju Brazylii, do każdego wprowadzając element dosłownie spoza czasu. W końcu, gdy trafia do Rio roku 2093, powtarza się sytuacja, w. której pierwszy raz Abeguar uświadomił sobie swoją moc: wraz z ukochaną Janaíną ponownie staje nad brzegiem przepaści - dawno temu był to amazoński las, teraz migające w dole miasto i ponownie unosi się w powietrze, uciekając korporacyjnej policji. Jak w Podłącz się anachronizm staje się narzędziem walki z opresyjnym systemem, będącym manifestacją neoliberalnych fantazji. Osiągnięcia prekolumbijskich cywilizacji przychodzą na pomoc również tytułowemu bohaterowi argentyńskiego Cóndor Crux. By pokonać demoniczną Gloria Mundi Corporation (przywodzi ona na myśl jedną z wielu organizacji, które w latach dziewięćdziesiątych rozkwitały pod rządami neoliberalnego prezydenta Carlosa Menema), dzielny pilot musi sięgnąć do dziedzictwa dawnych ludów. W praktyce autorzy filmu mieszają elementy kultur Majów, Azteków i Inków, nonszalancko wybierając z nich to, co pasuje do kina rozrywkowego[25] (w momencie premiery film był największym przedsięwzięciem argentyńskiej animacji). Nie zmienia to faktu, że Cóndor Crux jest jedną z manifestacji radykalnej reorganizacji czasu, w której synchroniczne rzuca wyzwanie diachronicznemu.

Podobną strategię, choć nienawiązującą już do kultur prekolumbijskich, stosują twórcy Anteny (La antena, 2007, reż. Esteban Sapir). Akcja filmu, słusznie określonego przez Joannę Page jako „retrofuturystyczny” [26], ma miejsce w bliżej nieokreślonej rzeczywistości, gdzie atrybuty późnego konsumpcyjnego kapitalizmu (dominacja telewizji) mieszają się z elementami zaczerpniętymi z lat trzydziestych i czterdziestych XX wieku, a także wizjami przyszłości, nawiązującymi chociażby do Metropolis (1927) Fritza Langa. W tym filmie zatem temporalny wymiar nowoczesności zostaje skomplikowany przez samą konstrukcję diegezy, podczas gdy imperatyw progresu zanegowany jest w warstwie

[24] Zob. A. Hummel, U. Ługowska, Ameryka indiańska, [w:] Dzieje kultury latynoamerykańskiej, red.

M.F. Gawrycki, Warszawa 2009, s. 147-149.

[25] Zob. J. Page, Polytemporality in Argentine science fiction film, [w:] Simultaneous Worlds. Global Science Fiction Cinema, red. J.L. Feeley, S.A. Wells, Minneapolis, London 2015, s. 147.
[26] Idem, Retrofuturism and reflexivity in Argentine science fiction film: the construction of cinematic time, "Arizona Journal of Hispanic Cultural Studies" 2012, vol, 16, s. 228. 
fabularnej: bohaterowie zwyciężają, gdyż sięgają po dawną - wydawałoby się, że przestarzałą - technikę.

W tym kontekście szczególnie interesująca wydaje mi się również peruwiańska Wideofilia (2015, reż. Juan Daniel F. Molero). Niełatwo ten film bezpośrednio wpisać w konwencje science fiction, jednak uważam, że Wideofilia porusza jeden z najważniejszych dla gatunku tematów: efektów totalnej integracji techniki z człowiekiem i społeczeństwem. W utrzymanym w estetyce glitch filmie Molero cały świat jawi się jako poroniony amalgamat GIF-ów, memów, wideo z kotami i pornograficznych klipów. Jednak w centrum Limy wciąż stoją prekolumbijskie ruiny, a Internet i telewizyjne wiadomości wieszczą koniec świata na podstawie kalendarza Majów. To, co w takich filmach jak Podłącz się jest wizją przyszłości, w Wideofilii już się dzieje. Postęp sprowadził chaos, ale zbawienia ciągle szukać można w anachronizmach: przestrzenią najbardziej sprzyjającą napędzanej LSD introspekcji bohaterki okazują się wspomniane wyżej pozostałości dawno wymarłej cywilizacji. Pośród ceremonialnych inkaskich huacas, po wezwaniu do bogini Pachamamy, technologiczna nowoczesność rozpada się: filmowy ekran zanieczyszczają zakłócenia, obraz pogrąża się w zniekształconych smugach glitchy. Zarówno w Wideofilii, jak i wyżej omówionych filmach, dyskurs rozwoju i postępu zostają sproblematyzowane. Jest to krytyka, o której pisał Walter Benjamin: skierowana przeciwko wyobrażeniu, że ludzkość posuwa się naprzód przez pusty i homogeniczny czas[27].

Jak zostało pokazane wyżej, latynoamerykańskie kino science fiction to często kino o wyraźnym nastawieniu krytycznym, które nie tylko wyobraża dystopię, ale również w subwersywny sposób ją podważa. Warto zaznaczyć, że to skierowanie w czasy cywilizacji prekolumbijskich (obecne w każdym omawianym filmie, z wyjątkiem Anteny) może kojarzyć się z błędem natywizmu, to znaczy pojmowaniem tego, co pierwotne, jako tego, co czyste. Uważam jednak, że przybliżone wyżej tytuły nie prezentują radykalnej negacji postępu, proponując zamiast tego swoistą hybrydyzację i negocjację nowej tożsamości w procesie odcinania się od kolonialnego dziedzictwa. Jest to tym bardziej intrygujące, że duża część omawianych produkcji (Bacurau, Antena, Wideofilia, wspomnieni niżej Nieoswojeni, 2016, reż. Amat Escalante) najprawdopodobniej nie powstałaby, gdyby nie wsparcie europejskich funduszy (m.in. holenderski Hubert Bals Fund, telewizja ARTE, norweski Sørfond, francuska Aide aux cinémas du monde). Takie zależności zawsze powinny budzić pytania o ewentualne zaistnienie neokolonialnych relacji władzy i podległości, czasem manifestujących się w treści filmów, mówiących Europejczykom po prostu to, co ci „chcieliby usłyszeć” [28], a unikających

[27] Zob. W. Benjamin, O pojęciu historii, [w:] idem, N. Elias, Anioł historii: eseje, szkice, fragmenty, red. H. Orłowski, Poznań 1996, s. 5/7. Fragment za: $<$ http://piotr.strebski.pl/wp-content/texts/philosophy/ Benjamino1.pdf>, dostęp: 18.04.2020.
Własny wszechświat
[28] Zob. R. Halle, Offering tales they want to hear: Transnational European film funding as neo-orientalism, [w:] Global Art Cinema: New Theories and Histories, red. R. Galt, K. Schoonover, New York 2010, s. 303-319. 
faktycznego międzykulturowego dialogu. Niemniej, omówione wyżej filmy wpisują się w popularny wśród latynoskich twórców trend tematyzowania obcych wpływów. Dotyczy on zarówno kolonialnej przeszłości (np. Rey - Król - 2017, reż. Niles Atallah), neoliberalnej teraźniejszości (np. A febre - Goraczka - 2019, reż. Maya Da-Rin), jak i - co zostało omówione w tym artykule - fikcji spekulatywnej. Filmowcy z Ameryki Łacińskiej otwarcie problematyzują globalny układ sił, w którym przyszło im funkcjonować.

Również wykorzystywanie konwencji science fiction do analizy lokalnych problemów wiąże się z kontrowersjami: jest to wszak konwencja często uznawana za napływową. Przyjęcie tego założenia oznaczałoby jednak - po pierwsze - zanegowanie partykularnych tradycji fantastyki naukowej w Ameryce Łacińskiej, oraz - po drugie - uznanie praktyk regionalnych filmowców za proste naśladownictwo, a nie pracę krytyczną, ciągle w tym kinie obecną.

W Kanibalistycznym manifeście brazylijskiego science-fiction (Ruch Supernova) (Manifesto Antropofágico da Ficção Científica Brasileira - Movimento Supernova, 1988) Ivan Carlos Regina pisał, że powielanie obcego modelu doprowadza do umysłowej biedy[28]. Dziś latynoamerykańskie science fiction to przestrzeń różnorodna i inkluzywna, w której odnajdują się także twórcy kojarzeni raczej z kinem festiwalowym niż gatunkowym. Amat Escalante w Nieoswojonych sprowadza na Ziemię tajemniczego przybysza z kosmosu, a Lucrecia Martel próbowała przenieść na duży ekran komiks El Eternauta (1957-1959), jedno z największych dokonań w historii gatunku[29]. Latynoscy twórcy opracowali własną formułę, pozwalającą im na wchodzenie w intrygujący dialog z otaczającą ich rzeczywistością.

Publikacja powstała $\mathrm{w}$ wyniku realizacji projektu badawczego o $\mathrm{nr}$ 2019/32/C/ HS2/o0495 finansowanego ze środków Narodowego Centrum Nauki.

Adam B., Time, Cambridge 2004

Alihodžić D., Veseljevic Jerkovic S., The Boundaries of Dystopian Literature: The genre in context, Tuzla 2016

Bell A., Science fiction in Latin America: Reawakenings, „Science Fiction Studies” 1999, nr 3, vol. 26, s. 441-446

Benjamin W., O pojęciu historii, [w:] W. Benjamin, N. Elias, Anioł historii: eseje, szkice, fragmenty, red. H. Orłowski, Poznań 1996, s. 5/7. Fragment za: <http://piotr. strebski.pl/wp-content/texts/philosophy/Benjamin01.pdf>, dostęp: 18.04.2020

Cua Lim B., Translating Time. Cinema, the fantastic, and temporal critique, Durham 2009

Deveny T.G., Migration in Contemporary Hispanic Cinema, Lanham 2012

[29] Za: R. Haywood Ferreira, The Emergence of Latin American Science Fiction, Middletown 2012, s. 218. [30] Lucrecia Martel, por qué el fracaso del proyecto de "El Eternauta” la llevó a „Zama”, „La Gaceta
Salta" 06.09.2017, <https://www.lagacetasalta.com. ar/nota/88774/espectaculos/lucrecia-martel-fracaso-proyecto-eternauta-llevo-zama.html>, dostęp: 9.04.2020. 
González Echevarría R., Myth and Archive: A Theory of Latin American narrative, Cambridge, New York, Port Chester, Melbourne, Sydney 2006

Halle R., Offering tales they want to hear: Transnational European film funding as neo-orientalism, [w:] Global Art Cinema: New Theories and Histories, red. R. Galt, K. Schoonover, New York 2010, s. 303-319

Haywood Ferreira R., The Emergence of Latin American Science Fiction, Middletown 2012

Hummel A., Ługowska U., Ameryka indiańska, [w:], Dzieje kultury latynoamerykańskiej, red. M.F. Gawrycki, Warszawa 2009, s. 147-149

Jameson F., Progress versus Utopia; or, can we imagine the future?, „Science Fiction Studies" 1982, nr 27, s. 147-158

Jameson F., Archaeologies of the Future: The desire called utopia and other science fictions, New York 2005

Langer J., Postcolonialism and Science Fiction, Houndmills, Basingstoke, Hampshire, New York 2011

Langer J., The shapes of dystopia. Boundaries, hybridity and the politics of power, [w:] Science Fiction, Imperialism and the Third World, red. E. Hoagland, R. Sarwal, Jefferson, London 2010, s. 171-187

Le Guin U., Introduction, [w:] The Norton Book of Science Fiction: North American science fiction, 1960-1990, red. U. Le Guin, B. Attebery, New York 1993

Liverman D.M., Vilas S., Neoliberalism and Latin American environments, „Annual Review of Environment and Resources" 2006, nr 1, vol. 31, s. 327-363

Lucrecia Martel, por qué el fracaso del proyecto de "El Eternauta" la llevó a „Zama", „La Gaceta Salta” 6.09.2017, <https://www.lagacetasalta.com.ar/nota/88774/ espectaculos/lucrecia-martel-fracaso-proyecto-eternauta-llevo-zama.html>, dostęp: 9.04.2020

Lyotard J.-F., The Inhuman. Reflections on Time, przeł. G. Bennington, R. Bowlby, Stanford 1998

Maj K.M., Antyutopia - o gatunku, którego nie było, „Zagadnienia Rodzajów Literackich" 2019, t. 62, nr 4, s. 9-29

McClintock A., Imperial Leather: Race, gender, and sexuality in the colonial contest, Abingdon-on-Thames 2013

Page J., Polytemporality in Argentine science fiction film, [w:] Simultaneous Worlds. Global Science Fiction Cinema, red. J.L. Feeley, S.A. Wells, Minneapolis, London 2015, s. 137-153

Page J., Retrofuturism and reflexivity in Argentine science fiction film: the construction of cinematic time, „Arizona Journal of Hispanic Cultural Studies” 2012, vol. 16, s. $227-244$

Petras J., Veltmeyer H., Neoliberalism and imperialism in Latin America: dynamics and responses, „International Review of Modern Sociology” 2007, vol. 33, s. 27-59

Racięski B., Argentyna, Meksyk, Brazylia oraz pozostałe kinematografie latynoamerykańskie, [w:] Historia kina, t. 4: Kino końca wieku, red. T. Lubelski, I. Sowińska, R. Syska, Kraków 2019, s. 605-640

Racięski B., Zapaśnik bawi i uczy. Społeczne funkcje filmów o Santo, [w:] Bękarty kinematografii, czyli rzecz o filmach nie(do)cenionych, red. B. Racięski, F. Nowak, J. Łuniewicz, Wrocław 2014, s. 113-126

Ross M., The film festival as producer: Latin American films and Rotterdam's Hubert Bals Fund, „Screen” 2011, nr 2 (52), s. 261-267

Schroeder Rodriguez P.A., Marxist Historiography and Narrative Form in Sergei Eisenstein's ¡Que viva Mexico!, „Rethinking Marxism” 2009, nr 2, vol. 21, s. 228-242, DOI: $10.1080 / 08935690902743393$

Spencer D., Clandestine Crossings: Migrants and coyotes on the Texas-Mexico border, Ithaca 2009 